\title{
REAÇÕES E REFLEXÕES DE ALUNOS DE INGLÊS DURANTE A LEITURA DE TEXTOS MULTIMODAIS ENTENDIDOS PELO VIÉS DAS PERSPECTIVAS CRÍTICAS
}

Reactions and Reflections of English Students While Reading Multimodal Texts as Seen by Critical Perspective Studies

\author{
Barbra SABOTA (UEG) ${ }^{1}$ \\ Jossane Rodrigues de OLIVEIRA (UniEVANGÉLICA) ${ }^{2}$
}

\begin{abstract}
RESUMO: Este estudo qualitativo interpretativo se pauta pelas premissas da Educação Linguística Crítica (ELC), para apresentar e discutir como textos imagéticos foram usados em aulas de inglês para promover momentos críticos e problematizadores junto aos alunos de uma turma iniciante ( 1 ano e meio de estudos do idioma) de um centro de idiomas - projeto de extensão universitária em uma cidade no interior de Goiás. A partir do planejamento de aulas sob o viés da multimodalidade busca-se garantir que os alunos/as pudessem questionar e repensar sobre suas realidades por meio da língua alvo, (re)construindo sentidos a partir dos textos. No estudo ocorre a oportunização aos alunos de debater os temas, demonstrando suas reações e reflexões a textos imagéticos multimodais em sala de aula. Percebe-se, ao responder as perguntas de pesquisa, a repercussão dos textos imagéticos mais discutidos preponderantemente os que mais se relacionam com suas vivências pessoais e profissionais (fatores como idade, curso e profissão, por exemplo) foram determinantes para maior engajamento dos/as alunos/as. Desse modo, pode-se afirmar que, pelos textos imagéticos, os alunos puderam ler a si mesmos reavaliando suas atitudes contemplando o que Menezes de Souza (2011) diz por ler-se lendo.
\end{abstract}

PALAVRAS-CHAVE: educação linguística crítica; inglês; textos imagéticos.

ABSTRACT: This qualitative interpretive study is based on the principles of Critical Language Education (CLC), to discuss how images presented as texts were used in English classes to promote critical moments and raise problematizing questions among students of a beginning group ( 1 and a half years of English studies) in a university language center in a city in the countryside of Goiás. By planning classes with multimodal texts we aimed at making sure students got to (re)think about their realities in the target language, (re) constructing meanings from the texts. In the study there is an opportunity for students to discuss the themes, demonstrating their reactions and reflections

\footnotetext{
${ }^{1}$ Professora no Curso de Letras e no Programa de Pós-Graduação stricto sensu em Educação, Linguagem e Tecnologias da Universidade Estadual de Goiás - Câmpus Anápolis de Ciências Socioeconômicas e Humanas. Doutora em Letras e Linguística pela Faculdade de Letras da UFG. Pós-doutora em Linguística Aplicada pela UnB. barbrasabota@gmail.com

2 Graduada em Letras pela Universidade Estadual de Goiás - Câmpus Anápolis de Ciências Socioeconômicas e Humanas. Aluna de Especialização do Curso Docência em Língua Inglesa pela UniEVANGÉLICA - Centro Universitário. jossoliveira@live.com
} 
about multimodal imaging texts in the classroom. In response to the research questions, the repercussion of the most discussed imagetic texts was predominantly about those related to their personal and professional experiences (factors such as age, course and profession, for example) were determinant for a greater commitment of the students. In this way, it can ensure that, through the imagetic texts, the students could read themselves re-evaluating their attitudes contemplating what Menezes de Souza (2011) means by read by reading yourself.

KEYWORDS: critical linguistic education; English; multimodal texts.

\section{APRESENTAÇÃO}

A Educação Linguística Crítica (doravante ELC) vem se definindo como uma área importante para o avanço da Linguística Aplicada Crítica por colocar em movimento algumas de suas premissas basilares: a percepção de língua como prática social, a valorização da agência discente e docente durante o processoeducativo, e a promoção constante do autoquestionamento a fim de possibilitar que os regimes de verdade sejam constantemente revisitados e favoreçam o combate de desigualdades e injustiças sociais (SILVESTRE, 2017; PENNYCOOK, 2001). As aulas, dentro desta praxiologia orientam-se pela escolha e problematização de temas críticos vivenciais.

Adotamos o 'termo crítico vivencial' inspiradas pela leitura dos textos de Silvestre (2017) e Rezende (2017). Para Silvestre (2017), os temas trabalhados em sala de aula com vistas a questionar a realidade e nosso modo de ser e estar no mundo consideram a "língua como inerentemente política" (SILVESTRE, 2017, p. 40), problematizam as relações de poder questionando o que se tem como certo e naturalizado e observam princípios éticos de cuidado com o próximo. Rezende (2017), por sua vez, referindo-se à definição desse sentido de 'crítico' usado por Silvestre ressalta que eles representam "atuações vivenciais, por dar vida aos temas de ensino e, assim, com novos/outros sentidos, sentidos prenhes de vida (...) [eles] promovem a reconfiguração ou ressignificação identitária e, assim, são temas-corpos, temas-vidas, temas vivências, temas vivenciais" (REZENDE, 2017, p. 283) e que, por isso, ampliam o sentido da práxis educativa.

Desse modo, para que os temas usados em nossas aulas pudessem oportunizar aos/às discentes vivências críticas propusemos atividades multimodais em aulas de inglês a fim de,por meio do estranhamento causado pelas imagens selecionadas, suscitarmos o debate. Tais atividades possibilitaram que ao estudar inglês, os/as 
aprendizes também pudessem rever seus posicionamentos em busca de"uma ação transformadora e que possibilite a mudança social" (FERREIRA, 2006 apud FREITAS, 2012, p. 80).

A inspiração para as aulas nos veio em uma conversa informal após um dos encontros em nosso grupo de estudos $^{3}$ no ano de 2017. Ao comentarmos sobre os vídeos e memes que estavam populares à época, decidimos adaptar a ideia para usarmos em sala de aula. Falávamos sobre os vídeos curtos (denominado "Teens React") produzidos por alguns youtubers ${ }^{4}$ que selecionavam amostras culturais de algum país, ou que retratavam algum aspecto social e mostravam para adolescentes a fim de registrar suas reações e debater sobre suas visões de mundo. Seguindo a sequência proposta pelos vídeos, reproduzimos o experimento social nas aulas de inglês de um grupo iniciante (um ano e meio de estudo de inglês) em um centro de idiomas que funciona como projeto de extensão comunitária em nossa universidade: a) selecionamos uma imagem (estática ou em movimento) para projetar; b) reunimos o grupo de estudantes em um momento da aula (as atividades duravam cerca de 30 minutos ao todo); c) registramos em vídeo a reação desses jovens às imagens visualizadas e os convidamos, em seguida, para refletir sobre suas reações. Em uma alusão ao tipo de vídeo que inspirou nossa iniciativa, intitulamos a atividade que ora relatamos "Student's React(ions)". Esta foi a fonte principal de material empírico gerado para a pesquisa que originou este artigo.

Assim, o objetivo neste estudo é compreender em que medida as reações dos alunos de língua inglesa aos temas apresentados nos textos imagéticos propostos ${ }^{5}$ durante o estudo ecoam reflexões crítico-vivenciais enquanto são incentivados a fazer leituras multimodais dos textos. $\mathrm{O}$ alcance do objetivo foi possível graças à prática problematizadora adotada pela professora da turma (uma das autoras deste texto) e pelo levantamento de alguns questionamentos feitos durante o desenvolvimento da pesquisa, quais foram: que textos problematizados em aulas de inglês na turma pesquisada mais repercutiram entre os/as alunos/as presentes; de que maneira as leituras feitas pelos

\footnotetext{
${ }^{3}$ O grupo de estudos TDELE -Tecnologias Digitais e Ensino - aprendizagem de Línguas Estrangeiras era parte integrante do projeto de pesquisa homônimo coordenado por uma das autoras deste estudo.

${ }^{4}$ Produtores de conteúdo digital para a plataforma de vídeo Youtube. Muitos vídeos produzidos por eles viralizam (tornam-se muito populares) e são repetidos com pequenas variações em seu formato original.

${ }^{5}$ Textos multimodais, neste artigo, são aqueles que empregam duas ou mais modalidades de formas linguísticas, a partir da composição da linguagem verbal e não verbal com o objetivo de proporcionar uma melhor inserção do leitor no mundo contemporâneo (MONTE MÓR, 2018).
} 
estudantes durante o debate refletem o entendimento deles sobre os temas críticovivenciais propostos e c) se há indícios de que a leitura dos textos multimodais tenha impactado de algum modo as produções orais e escritas desses alunos. Pretendemos revistar essas questões ao longo da análise.

Recorremos a autores como Freitas (2012), Jordão (2013), Martins e Souza (2015), Menezes de Souza (2011), entre outros, para embasar nosso entendimento no sentido de mostrar como e em que medida a atitude problematizadora ${ }^{6}$ proposta pela ELC, pode favorecer a percepção de língua como prática social, como uma ferramenta para entender e questionar o mundo enquanto o constrói e o ressignifica.

Ao refletir sobre como o ato de expressar-se em uma outra língua pode envolver, além das habilidades básicas, a capacidade de se indignar perante fatos e coisas e reagir linguisticamente a isso e, nesse sentido, por entender que esta língua soma ao que trazemos conosco em experiências e saberes é que, tal como Jordão (2014), optamos por chamá-la de língua adicional, em oposição ao termo 'estrangeira', que carrega a tônica do distanciamento, deixando o usuário como um expectador passivo perante suas possibilidades de realização (JORDÃO, 2014).

Partindo do pressuposto de que não é necessário/possível dissociar língua e prática social, buscamos construir sentidos outros sobre temas corriqueiros que preenchem nosso cotidiano e que, por vezes são naturalizados e silenciados em nossas salas de aulas. Para Jordão (2006) a educação linguística crítica valoriza, em sua praxis, "o contato com procedimentos alternativos de construção de sentidos, com perspectivas diferenciadas sobre os acontecimentos, com maneiras variadas de entender o mundo" (JORDÃO, 2006, p. 8). Nesse processo de entender o mundo é que se torna possível agir de modo a provocar mudanças significativas para o sujeito e para a comunidade a que pertence, pois mexemos com os processos de reconstrução desubjetividades dos indivíduos. Deste modo, é importante acolher e prezar pela maneira como as emoções são percebidas e expressas em salas de aula com viés crítico. O grande investimento pessoal na construção de argumentos quando tratamos de temas tão próximos do/a aprendiz, como nos casos da reflexão a partir de temas críticos vivenciais, pode

\footnotetext{
${ }^{6}$ Atitude problematizadora significa discutir aspectos complexos, difíceis; Questionar, indagar, formular idéias, conceitos.
} 
provocar processos de deslocamentos de certezas que desestabilizam os indivíduos e pede uma escuta sensível por parte do docente (SILVESTRE, 2017).

\section{ASPECTOS METODOLÓGICOS CONCERNENTES AO ESTUDO}

Esta pesquisa foi desenvolvida como um estudo de caso entendido sob parâmetros qualitativos-interpretativos, o que equivale a dizer que o material empírico gerado foi revisitado pelas pesquisadoras na intenção de construir sentidos a partir do que percebemos em cotejamento com nossos estudos teóricos e nossa vivência pessoal e profissional. Para Robson, o estudo de caso é "uma investigação empírica que analisa fenômenos contemporâneos dentro de seu contexto real utilizando múltiplas fontes de evidência" (ROBSON, 1993, p. 147). O autor destaca que esta é uma modalidade de pesquisa adequada quando se tem um pequeno número de participantes e se pretende entender suas ações em contexto de modo aprofundado, como é o caso de nossa pesquisa. Para assegurar que teríamos material empírico diversificado, elaboramos um questionário para obter informações específicas do perfil de cada aluno/a e um roteiro (semiestruturado) para a condução de entrevistas ao final do processo de geração de material empírico.Uma das pesquisadoras encarregou-se de ministrar as aulas, conduzir rodas de conversa e registrar esses momentos em áudio e vídeo para posterior transcrição, no entanto, o roteiro para as aulas e a análise das transcrições ocorreu em conjunto. Contamos também com amostras das produções (escritas multimodais) também compõem o material empírico deste estudo ${ }^{7}$.

O caso que ora estudamos conta com 11 participantes: a professora e dez alunos/as de inglês do centro de idiomas (Básico $4-1$ 1/2 anos de estudo do idioma). Apresentamos, a seguir, um quadro com algumas informações sobre os/as participantes ${ }^{8}$ (identificados por pseudônimos). Como pode ser percebido no quadro a maioria dos participantes são jovens entre 18 e 22 anos (seis entre onze participantes), estudantes (seis entre onze paticipantes), de pele branca (sete entre os onze participantes) do sexo feminino (oito entre onze participantes). Apesar de o estudo de caso não ter foco na generalização de dados, é interessante perceber qual o perfil de alunos/as

\footnotetext{
${ }^{7} \mathrm{O}$ material empírico foi gerado para o trabalho de conclusão de curso de uma das autoras. Este artigo utiliza apenas um recorte desse material gerado para a discussão proposta aqui.

${ }^{8}$ Os/as alunos/as assinaram um termo de consentimento permitindo o uso acadêmico do material empírico gerado neste estudo.
} 
atendendidos/as pelo centro de idiomas nesta turma, pois tais informações nos auxiliam a compreender seus locais de fala.

Quadro 1 - Apresentação dos/as participantes do estudo

\begin{tabular}{|c|c|c|c|c|}
\hline Pseudônimo & Idade & Oсирас̧а̃o & Cor da pele & Gênero \\
\hline Ana & 18 anos & $\begin{array}{l}\text { Estudante do curso de Biologia da Universidade } \\
\text { Estadual de Goiás. }\end{array}$ & Branco & Feminino \\
\hline Anne & 18 anos & $\begin{array}{l}\text { Estudante do } 3^{\circ} \text { ano do Ensino Médio pelo Instituto } \\
\text { Federal de Educação, Ciência e Tecnologia de } \\
\text { Goiás. }\end{array}$ & Pardo & Feminino \\
\hline Jade & 20 anos & $\begin{array}{l}\text { Estudante do } 4^{\circ} \text { período do curso de Economia da } \\
\text { Universidade Estadual de Goiás; Estagiária na área. }\end{array}$ & Branco & Feminino \\
\hline Joss & 24 anos & $\begin{array}{l}\text { Professora de inglês no Centro de Idiomas da UEG. } \\
\text { Estudante do } 8^{\circ} \text { período de Letras da Universidade } \\
\text { Estadual de Goiás. }\end{array}$ & Branco & Feminino \\
\hline Kiko & 32 anos & $\begin{array}{l}\text { Gerente de Tecnologia; técnico em informática. } \\
\text { Ensino Médio Completo. }\end{array}$ & Pardo & Masculino \\
\hline Maria & 22 anos & $\begin{array}{l}\text { Estudante do curso de Arquitetura e Urbanismo da } \\
\text { Universidade Estadual de Goiás. }\end{array}$ & Branco & Feminino \\
\hline Nicky & 35 anos & $\begin{array}{l}\text { Psicóloga clínica e especializada em psicologia } \\
\text { hospitalar. Curso superior completo em Psicologia. }\end{array}$ & Branco & Feminino \\
\hline Ted & 21 anos & Estudante de Ciências da computação & Branco & Masculino \\
\hline Tícia & 28 anos & $\begin{array}{l}\text { Estudante do } 3^{\circ} \text { período do curso de Administração } \\
\text { pela Universidade Estadual de Goiás- CSEH; } \\
\text { Estagiária de Administração Geral da UEG - } \\
\text { Câmpus CET. }\end{array}$ & Pardo & Feminino \\
\hline Tom & 48 anos & Advogado, especialista em Direito do Trabalho. & Pardo & Masculino \\
\hline Yana & 19 anos & Auxiliar de venda. Ensino Médio Completo. & Branco & Feminino \\
\hline
\end{tabular}

Fonte: Elaborado pelas pesquisadoras a partir do material empírico.

O curso do Básico 4 é organizado em 15 encontros de 2 horas e 30 minutos cada. Os/as professores/as usam um livro base, mas podem complementá-lo e/ou realizar alterações no programa desde que haja a anuência da professora coordenadora do centro de idiomas ou de uma professora orientadora em um projeto, como foi o nosso caso. Usamos cerca de 30 minutos em 10 aulas para gerar o material base deste estudo. No entanto, neste artigoselecionamos amostras de dois encontros cujas discussões consideramos mais representativas da reflexão crítica que pretendemos discutir adiante. 
Quadro 2 - lista de textos multimodais usados nos encontros

\begin{tabular}{|c|c|c|}
\hline Encontros & Textos multimodais & Fonte \\
\hline $\begin{array}{l}\text { Encontro } 1- \\
05 / 10 / 2017\end{array}$ & $\begin{array}{l}\text { Temas: Redes sociais e tecnologias digitais. } \\
\text { Textos multimodais usados (imagens } \\
\text { estáticas): } \\
\text { 1. Zumbis tecnológicos } \\
\text { 2. Pokémon GO } \\
\text { 3. Ovelha-cérebro e o facebook }\end{array}$ & $\begin{array}{l}\text { 1. http://www.stevecutts.com/ } \\
\text { 2. http://zelmar.blogspot.com/2016/07/pok } \\
\text { 3. } \frac{\text { https://i.ytimg.com/vi/djZffniaYgA/mq }}{\text { default.jpg }}\end{array}$ \\
\hline $\begin{array}{l}\text { Encontro } 8- \\
16 / 11 / 2017\end{array}$ & $\begin{array}{l}\text { Temas: representação da mulher na sociedade } \\
\text { atual. Textos multimodais usados (vídeos): } \\
\text { 1. Melhor comercial de aspirador de pó } \\
\text { 2. Evolução da mulher (Women's Evolution) }\end{array}$ & $\begin{array}{l}\text { 1. } \frac{\text { https://www.youtube.com/watch? } \mathrm{v}=\mathrm{ty}}{\text { sJ8w WkmM }} \\
\text { 2. } \underline{\text { https://www.youtube.com/watch? } \mathrm{v}=\mathrm{O}} \\
\underline{\mathrm{D} 2 \mathrm{XOX} \text { OwWiY }}\end{array}$ \\
\hline
\end{tabular}

Fonte: Elaborado pelas pesquisadoras a partir do material empírico.

A curadoria das imagens propostas para as leituras foi feita a partir dos critérios: retratar o tema crítico vivencial da aula com um toque de humor e/ou ironia; fazer alusão a uma crítica social identificável e ser encontrada em uma rede social e/ou em um repositório de modo gratuito. Os temas para as aulas foram selecionados pelas autoras deste texto à época do planejamento da experiência por serem recorrentes na programação da mídia convencional com repercussão ampla nas redes sociais.

Os textos multimodais foram exibidos aos/às participantes através do datashow por meio de slides elaborados no computador pela professora pesquisadora no programa powerpoint. Os vídeos foram buscados na internet na plataforma gratuita YouTube a partir da pré-definição do tema a ser abordado. Após a sequência já explicada anteriormente para abordar os textos multimodais em aula (seleção - visionamento debate), inserimos uma produção textual para que os estudantes tivessem a oportunidade de se expressarem sobre pontos que talvez não tivessem mencionado durante a aula. Além disso, a produção textual representava uma oportunidade a mais para que utilizassem o idioma em estudo na emissão de opiniões e registro dos debates travados em aula. Na entrevista, realizada ao final da pesquisa, retomamos alguns pontos que nos chamaram a atenção durante a geração dos dados. Na sequência, trazemos nosso material empírico à luz de nossos estudos e reflexões teóricas. 


\section{PERSPECTIVAS CRÍTICAS EM AULAS DE INGLÊS - AÇÕES, REAÇÕES E EMOÇÕES}

Explorar a educação linguística crítica partindo de discussões em classe e enxergá-la como prática de reflexão e desenvolvimento de relações sociais, conecta-se ao que Hooks sugere quanto a se buscar "fazer da sala de aula um contexto democrático onde todos/as sintam a responsabilidade de contribuir, sendo [este] um objeto central para a educação transformadora" (HOOKS, 2013, p. 56). Ousamos afirmar que trabalhar com os textos imagéticos desestabilizaram nossos saberes docentes e nos trouxe gratas surpresas em relação ao que os/as participantes do estudo tinham a dizer. Percebemos que a sala de aula pode, de fato, ser considerada um espaço de reflexão e construção de indivíduos críticos, um ambiente social no qual ocorrem manifestações que trazem a realidade dos aprendizes para o centro de debate favorecendo que atuem na língua adicional com vistas à expansão de seus repertórios interpretativos, tal como observado por Sabota, Silva e Almeida (2018). Pudemos vivenciar com esta experiência o que Freitas afirma acerca da ELC, pois foi possível "suscitar a dúvida por meio do diálogo e da problematização das desigualdades sociais, [sem visar] converter ou convencer os(as) alunos(as) a acreditarem no que acreditamos ser politicamente correto" (FREITAS, 2012, p. 91).

A leitura e interpretação de textos pelo viés do letramento crítico ressignificado (MENEZES DE SOUZA, 2011) implica em perceber o processo de compreensão de um texto como uma construção subjetiva e individual de sentidos a partir das vivências sócio-históricas e culturais do/a aprendiz. Neste processo as visões de mundo macro (social) e micro (individual) se fundem a partir do modo como os leitores se vêem no texto, desse modo, a compreensão textual está subordinada às relações que são travadas entre leitor/a-texto/mundo durante o processo de leitura. Nesse sentido, cabe ao/à leitor/a e desafiar o texto, buscando o dissenso e a reinvenção de sentidos possíveis ressignificando-se também neste percurso. Menezes de Souza explica este processo como "ler se lendo", ou seja, ler se implicando com o texto deixando-se afetar por ele assumindo o papel de "construtores e atribuidores de sentidos às coisas" (MENEZES DE SOUZA, 2011, p. 296). Referindo-se ao modo didático de usar textos em aulas de línguas e contemplar o que é esperado nas ações de letramento, Silvestre se reporta a Luke e Dooley para ressaltar como textos podem ser usados a fim de "analisar e transformar relações culturais, sociais e políticas de poder" (LUKE; DOOLEY, 2009, p. 
01 apud SILVESTRE, 2014, p. 66) facilitando o processo de deslocamento dos sujeitos para além de seus regimes de verdade (as crenças que embasam suas ações e/ou opiniões).

Nessa esteira, entender como o uso de textos multimodais participam da vida do/a aprendiz e que sentidos são criados a partir do que vêem torna-se muito relevante nos dias atuais para se contribuir para o letramento crítico de aprendizes. Para além dessas questões, há de se considerar ainda o quanto a utilização de textos que povoam o cotidiano dos/as alunos/as (ou seja, com os quais os indivíduos convivem fora do contexto escolar) auxilia na ruptura de fronteiras do espaço escolar - o lá e o cá entre a sociedade (vida real) e a escola (simulação de situações da vida) como discutido por Sabota, Silva e Almeida (2018). Para a autora e os autores, romper com essas fronteiras entre a escola e o mundo auxilia no movimento de repensar a escola e o papel que ela ocupa na formação dos sujeitos, pois provoca desestabilizações nas verdades pessoais que aprisionam as interpretações (SABOTA; SILVA; ALMEIDA, 2018) e criam oportunidades de propícias à expansão do habitus interpretativo dos/as alunos/as (MONTE MOR, 2018), visando entender e voltar os olhos para o mundo em que estamos inseridos (e ajudamos a constituir) e não ficarmos presos em redomas alheios às discussões sociais.

Os textos imagéticos usados no estudo configuram-se como textos multimodais, ou seja, textos híbridos (unindo imagens e textos, aliados a marcas e/ou sons e movimentos) que nos permitem relacionar com a sociedade e com o que ela representa por meio dos sentidos construídos (OLIVEIRA, 2006; MONTE MÓR, 2018). A seguir, trazemos um dos textos utilizados em sala de aula para ilustrar o que foi debatido em um dos encontros. Nele vemos a representação de um cérebro no formato de uma ovelha, presa ao ícone que remete ao site de rede social facebook, alimentando-se de pequenas anotações que podem aludir aos textos postados neste site de rede social. 
Texto Multimodal 1 - Ovelha - cérebro e o facebook

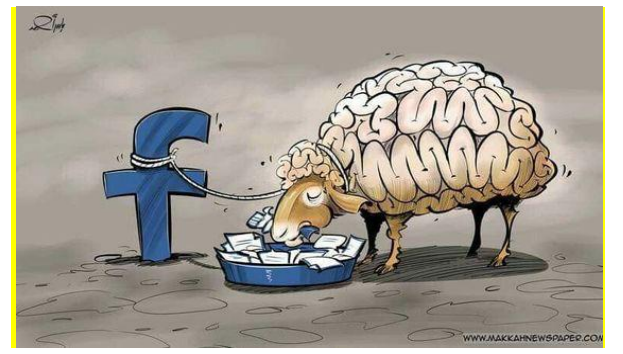

Fonte: Conta de Facebook Shift: A Movement from the Mainstream. ${ }^{9}$

Cabe observar como a passividade esperada pelo usuário da rede social facebook, indicada pelo "f”" azul minúsculo à esquerda é representada pela ovelha em forma de cérebro que consome irrefletidamente o conteúdo fornecido, amarrada à imagem da rede. Após o visionamento desta imagem os alunos travaram o diálogo parcialmente transcrito ${ }^{10}$, como se observa:

[1] Joss: So tell me what you guys see in the picture.

Maria: A sheep, a brain.

Nicky: The Facebook is controlling the sheep and the brain.

Joss: Why?

Maria: because it's good

Joss: [risos] What's good?

Maria: Mas é tipo um bom mau, entendeu? As pessoas não sabem usar, elas usam desesperadamente e inconsequentemente. Não sabe impor um limite.

Tom: The sheep is a quiet animal.

(Transcrição de vídeo, 05/10/2017)

Ao serem questionados sobre suas reações em relação à imagem,destaca-se no diálogo a fala direta de Nicky e a explicação de Maria, que indiretamente concorda com a fala de Nicky, respondendo a pergunta da professora sobre o motivo pelo qual as alunas inferem que o Facebook controla a ovelha em forma de cérebro. Maria, ao trazer sua visão sobre o assunto, esclarece que a rede social é um tipo "bom mau”, no sentido que não temos controle de uso desse aplicativo. Tal afirmação demonstra que a relativização do tema proposta pela aluna pode significar uma reflexão mantida neste momento sobre algo que é corriqueiro na vida dos jovens de hoje - o uso de redes sociais digitais. Percebemos, nessa situação, que Maria trouxe para a reflexão do texto imagético afirmações as quais automaticamente provocam um autoquestionamento que

\footnotetext{
${ }^{9}$ Disponível em: https://i.ytimg.com/vi/djZffniaYgA/mqdefault.jpg Acesso em: 03 out. 2017.

${ }^{10}$ As transcrições foram feitas buscando manter-se fiel ao que foi dito, sem realização de correções e/ou traduções das falas. Desse modo, fica mais evidente quanto e como o inglês foi produzido e em que momentos os estudantes recorrem ao português.
} 
leva a pensar se, de fato, sabemos, como usuários, refletir sobre como atuamos nas redes sociais em geral, desnaturalizando a opinião emitida e desafiando o senso comum. Tom, ao final da interação, reforça a ideia de passividade ao ressaltar o perfil pacífico do animal, que pode ser interpretado como nossa passividade perante as redes.

Importante notar como, em face de uma vontade súbita de se expressar além do que talvez sua fluência lhe permitia, Maria elabora uma resposta em português à provocação da professora. Esta transição da língua inglesa para a portuguesa, e viceversa, entre os alunos não deve ser vista como prejudicial, haja vista que o translinguar $^{11}$ auxilia a manter o foco no tema e a participação na interação. Este translinguarpode ser explicado pela complexidade das discussões travadas pelos alunos e pelo ímpeto de dar uma resposta breve. No entanto, como se observa, sem que seja necessária a intervenção docente, eles retornam à língua em aprendizagem. Eles entendem que devem buscar praticar o inglês, mas também demonstram autonomia para transitar entre as línguas sem perder o foco do debate. Como afirma Jordão, "a língua é discurso, espaço de construção de sentidos e representação de sujeitos e de mundo." (JORDÃO, 2013, p. 73) e a construção de sentidos não pode se limitar ao uso exclusivo de um idioma, visto que ambos compõem o repertório linguístico desses aprendizes. Desta forma, a aprendizagem de outro idioma ocorre em suporte com a língua materna e, consequentemente, facilitando a aprendizagem.

Ao ler criticamente as pessoas se percebem no texto - "ler, se lendo", e assim como em uma relação entre leitor e autor onde ambos podem construir, interpretar significados e emoções através da linguagem, ambos professor e aluno tem a liberdade de, por meio da linguagem, revisitar suas emoções para refletir, interpretar suas reações e rever seus valores para uma possível transformação pessoal.

O uso excessivo de tecnologias digitais foi abordado em relação à passividade com que nós, usuários, temos nos portado em relação às ferramentas e suportes. Os textos a seguir representam tal passividade por meio de personagens do repertório do universo dos jovens do século 21 , como pokémon e zumbis, relacionando-se com as tecnologias digitais.

\footnotetext{
${ }^{11}$ Translinguagem se refere ao processo que envolve "a aprendizagem dos alunos de duas línguas pelo processo de profundo engajamento cognitivo bilíngue" permitindo que oscilem entre elas ao longo das interações comunicativas (GARCÍA, 2015, p. 224). Grosso modo, translinguar é transitar entre línguas.
} 
Texto Modal 2 - Pokémon GO, Texto Modal 3 - Zumbis tecnológicos

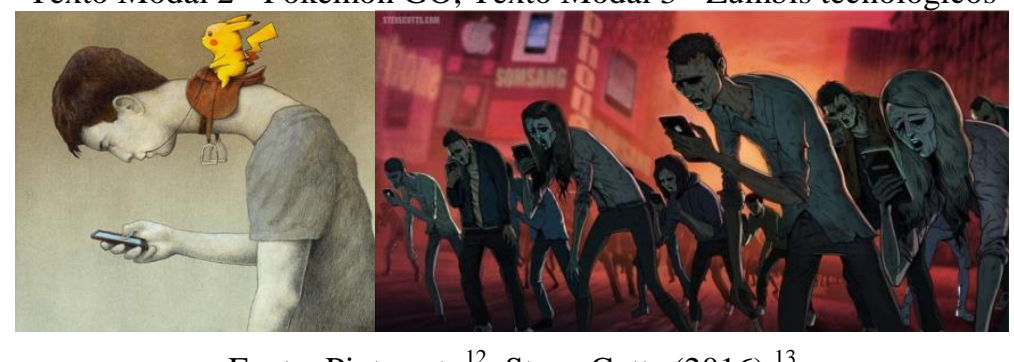

Fonte: Pinterest. ${ }^{12}$, Steve Cutts (2016). ${ }^{13}$

$\mathrm{Na}$ produção textual entregue por Kiko à professora foi perceptível como o aluno reflete sobre o hábito de jogar (jogos digitais), a princípio reservado a momentos de lazer, pode se tornar um vício.

[2] The uncontrolled use of technology or, in this case, a game, can cause addiction. This picture shows a character of the game named Pokémon GO controlling the man. But why the people let be controlled by things? The reason that lets someone under control of something, like a game, could be the necessity to be part of something, like a huge game community, the feeling of some joy. Anyway, we need to understand and control the time we spend on games, or on TV, or on mobile. (Kiko - produção textual).

Relacionando os textos debatidos nesta aula, podemos perceber como os discursos se entrelaçam. A falta de limite atribuíba por Maria [1] à imagem da ovelhacérebro se alimentando do conteúdo do facebook e o pensamento de Kiko [2] caminham na mesma direção. Ambos reiteram que o uso exagerado da tecnologias digitais pode controlar o ser humano, dando a ideia de que esses recursos tecnológicos podem preencher um vazio momentaneamente em suas vidas, trazendo um sentimento de alegria. Esse sentido construído em momentos distintos de produção (oral e escrita), pelos participantes durante a interação em aula e que reverberaram nos discursos uns dos outros mostra que houve colaboração interpessoal e genuína na construção desses sentidos produzidos durante a aula. Sempre que o tema das aulas voltava-se para tecnologias digitais, Kiko, por trabalhar diretamente com o uso da tecnologia (ele é técnico em informática), se mostrava bem ativo na maioria das discussões o que reitera a importância de unir as discussões que se passam na vida das pessoas com o que ocorre em ambientes educacionais (SABOTA; SILVA; ALMEIDA, 2018). Durante a entrevista, alguns alunos foram questionados se os debates os fizeram refletir sobre sua

\footnotetext{
${ }^{12}$ Disponível em: https://br.pinterest.com/pin/318277898649367176/. Acesso em: 06 ago. 2016.

${ }^{13}$ Disponível em: http://www.stevecutts.com/. Acesso em: 01 jan. 2016.
} 
realidade e os alunos ressaltam como isso agrega saberes à sua vida pessoal e profissional.

[3] Yes, a lot, especially when the images were about technology, because I work with technology and then I sometimes take this to my house, and this is not good. (Entrevista - Kiko, aula 10, 18/01/18)

[4] Sim, ainda mais que eu sou muito ligada a essas coisas discutidas (tecnologia), muitos assuntos debatidos me tocaram. (Entrevista - Anne, aula $10,18 / 01 / 18)$

[5] No, like I said, I'm an old man. I have seen so many things. Sometimes I'm disappointed with the youth, because they don't think outside the box. I always try to think outside the box. (Entrevista - Tom, aula 10, 18/01/18)

Aqui é possível perceber que Kiko e Anne repensam suas práticas sociais pelos textos imagéticos propostos. Chama a atenção a leitura que Tom, o mais velho da turma (48 anos), se coloca em relação à juventude. Ele lê seus colegas como "dentro da caixa", se opondo a isso e alertando que as leituras das situações são múltiplas. Outras alunas também refletiram sobre a presença do tema em suas vidas, mostrando como as aulas com temas vivenciais críticos podem extrapolar as fronteiras da sala de aula. Ana e Yana compartilham da preocupação sobre excessos em redes sociais, tema cada dia mais atual em tempo de fake news e pós verdades, vejamos suas ponderações.

[6] Um dos temas que me chamou mais atenção foi a discussão realizada a respeito das redes sociais consumirem a vida das pessoas. Umas das imagens o homem estava preso ao símbolo do facebook e a outra imagem era um homem sendo "alimentado" pelo facebook. Com base nas duas imagens, pode-se perceber que atualmente não só o facebook mas outras redes sociais consomem as pessoas e muitas pessoas vivem para ganhar curtidas, etc. As redes sociais não consomem apenas a parte física mas também a parte intelectual do ser humano. Contudo, ela também pode ser utilizada de maneira que leve informações úteis para si mesmo e outras pessoas. (Ana produção textual)

[7] Não me lembro de muitas imagens, mas as que chamaram minha atenção e me fez refletir foram sobre as redes sociais, apesar delas nos ajudarem a se comunicar com os que estão distantes, nos distanciam dos que estão perto. Existem muitas pessoas que usam esses meios de comunicação para o trabalho, como modo de pesquisas ou como uma válvula de escape para os problemas da vida real. Creio que é importante aprender a achar o equilíbrio dessas redes sociais para não se tornarem vícios o que pode afetar a execução das atividades do cotidiano. (Yana - produção textual)

Os temas debatidos em sala, como visto nos excertos, promoveram movimentos de autoquestionamento e que indicam mudanças que também se estenderam para a vida dos/as alunos/as, fazendo com que refletissem sobre seus hábitos, escolhas e o modo 
como constroem sentidos cotidianamente. As alunas ficaram impelidas a opinar, embora não se sentissem aptas a fazê-lo em inglês, portanto, entregaram suas reflexões em uma produção textual elaborada em língua materna. Como atividade subsequente, a docente da turma as incentivou a tentar trazer as mesmas reflexões no inglês, a fim de que pudessem exercitar o idioma além de contribuir com sua opinião que foi validada pela atitude da docente.

Outra questão fortemente observada no estudo foi o modo como os/as alunos/as tornaram-se autores/as de sentidos, atores construindo as falas em debates e não apenas participantes em uma atividade em grupo. Para Lier ,"agência não é simplesmente um traço característico ou atividade, mas um caminho contextualmente promovido de estar no mundo" (LIER, 2008, p. 01). Isso é observado nos depoimentos dos/as participantes que relatam-se orgulhosos de seu progresso e cientes de seu dever de aprendiz de língua adicional. Conseguimos perceber que para eles/as, a relação não foi estrangeirizada, mas sim bem próxima do que fazem na vida cotidiana, assim, o inglês representa uma adição às habilidades do sujeito intercultural e crítico que vão se construindo ao longo das aulas, como mostra o excerto a seguir.

[8] Well, my first reaction was: It's amazing! Now I have to learn how to think and talk in English. This challenge helps me a lot. For next year, I hope to continue in some way. In my opinion, when you try to build or make thoughts in other languages it's very hard. You will learn and never forget your new vocabulary. The Discussions showed me a new world. Pretty often the English classes are so boring. I liked the discussions. I appreciate this method because it pushes me over my borders. After every class, I tried to remember all the pictures and when I was alone, I talked to myself about them. (Entrevista - Tom, aula 10, 18/01/18)

Tom, através de seu excerto, afirma que as discussões em classe foram um desafio para ele, no entanto, um desafio que representou um convite ao aprimoramento de suas habilidades, algo que lhe mostrou diferentes possibilidades de entender o mundo e de estudar inglês. Depoimentos assim nos animam a continuar trabalhando nesta perspectiva, a despeito das adversidades e dificuldades (como enfrentamentos políticos e acréscimo do volume de trabalho com a elaboração de materiais didáticos, por exemplo). Tom ressalta como os debates promovidos nas aulas o ajudaram a ampliar o questionamento sobre temas e como isto o acompanha após as aulas. Entendemos que a possibilidade de continuar a reflexão após o evento da aula prolonga o tempo de contato com o que tem sido discutido no espaço escolar, renova o interesse pela aprendizagem e 
amplia os desdobramentos das aulas de línguas na vida social. É perceptível ainda a ampliação de repertórios com os quais se pode ler o mundo. Segundo Jordão "a multiplicidade de sentidos possibilitada pelas diversas ideologias é tida como algo produtivo: ao invés de uma realidade por trás da ideologia perniciosa, temos aqui muitas verdades construídas ideologicamente e partilhadas socialmente" (JORDÃO, 2013, p. 76). Neste sentido, os temas crítico-vivenciais surgem com esse intuito: gerar debates, contestações e diferentes críticas e apreciações partilhadas em conjunto em busca do dissenso apregoado pelo letramento crítico ressignificado (MENEZES DE SOUZA, 2011).

Para Maturana, "somos humanos na linguagem e ao sê-lo, o somos fazendo reflexões sobre o que nos acontece" e "se não estamos na linguagem, não há reflexão, não há discurso" (1998, p. 37-38 apud MARTINS; SOUZA, 2015, p. 64). Por isto, antes de todos os debates, somos seres humanos na linguagem, e agimos de acordo com nossas emoções. Aragão defende que

ao mudar de emoção, mudamos de domínio de ação, num fluir que Maturana chama de emocionar. Um domínio de ação é um domínio de condutas, comportamentos, posturas ou atitudes corporais que um observador distingue com uma emoção: é a emoção, e não a razão, que define a ação, embora em geral nãotenhamos dificuldade de justificar racionalmente nossas ações (ARAGÃO, 2005, p. 105-106).

Em outras palavras, nossas emoções são movidas por nossas ações e reações e são elas que definem nossas ações e não a razão, sobretudo diante do inesperado, como foi o caso desta experiência didática.

No encontro 8 tratamos da representação da mulher na sociedade atual. Foram apresentados textos que exploram o padrão de beleza feminino fazendo emergir a discussão sobre as mudanças que o corpo feminino sofre para ser considerado socialmente "belo". No material estava implícita uma crítica aos procedimentos estéticos que esculpem e marcam o corpo feminino adequando-o à expectativas que nem de longe pautam-se pelo bem estar ou saúde física da mulher. Estes textos tocaram sobremaneira às participantes do sexo feminino que, via de regra, reagiram concordando com as transformações sofridas.

No primeiro vídeo é mostrada uma garota de biquíni que tem partes de seu corpo aspiradas por um aspirador de pó. Fazendo uma alusão à lipoescultura (procedimento médico hospitalar invasivo que aspira a gordura corporal excedente), o texto remete ao 
quão comum é tal procedimento nos dias atuais e a praticidade com que as pessoas aderem a ele.

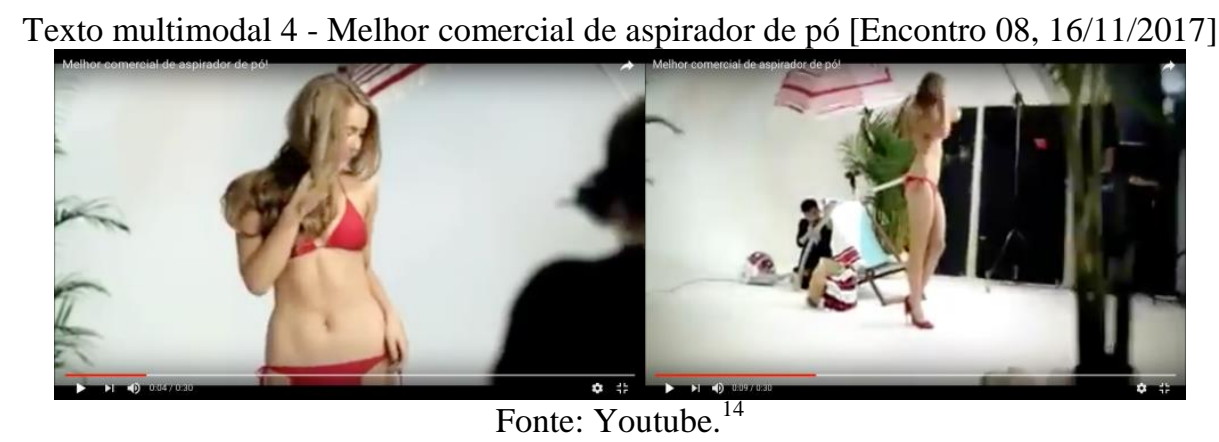

Após o visionamento, seguiu-se o seguinte diálogo:

[9] Joss: Okay, let's talk about this video,

Todos: Wooooooow![risos] Wow!

Nicky: quero um desse!

Joss: Yeah, me too [risos]. I wish I had one of those, it should be expensive right?

Tícia: Very expensive!

Joss: So what do you guys think?

Tícia: umm, it's funny.

Tom: [risos] but you can't do the impossible.

Todos: Yes, impossible.

Joss: Do you guys think this is a real commercial or a fake one? Fake, not real?

Todos: Fake.

Joss: Why?

Maria: because it's impossible [risos]

Joss: It's Impossible?

Todos: Yes,it's impossible for one to be sucked up.

Tom: For everybody! But exactly, you can think about the vacuum, and there is a tool in the back in the shopping to buy??

(Transcrição de vídeo, aula 08, 16/11/2017)

Neste excerto, Nicky declara que se interessaria pelo produto proposto no vídeo. Entretanto, tanto os homens como as mulheres concordam com a mesma ideia de que seria impossível acontecer o que estaria sendo feito com a mulher no texto multimodal. Assim, a professora entra em acordo com a fala dos/as alunos/as no sentido de que também gostaria de ter um aspirador com as mesmas funções. É interessante notar como, às vezes, no processo de formação do professor crítico, o docente é pego de

\footnotetext{
${ }^{14}$ Disponível em: https://www.youtube.com/watch?v=tysJ8w WkmM. Acesso em: 02 out. 2013.
} 
surpresa quanto à suas próprias reações. Apesar de ter se preparado para discutir o tema e a despeito das leituras já feitas sobre o assunto, a voz do patriarcado que constitue nossas identidades (ainda que contra nossa vontade, controlando nosso desejo) falou mais alto. Ou seja, o fato de ter preparado a aula, pensado sobre o tema não garantiu automaticamente uma transformação imediata na realidade da professora. Não seria justo esperar que para os/as alunos/as fosse diferente. A mudança é lenta, no entanto, contínua. Por isso é fundamental para que haja a transformação de hábitos que mudem uma cultura opressora, tal como a que estamos inseridos. Para que vejamos o corpo feminino com mais respeito e pelo que ele é torna-se fundamental que repensemos nossos posicionamentos. Entendemos que a educação linguística crítica tem muito a contribuir nesta seara. A medida que discutimos e provocamos na e pela língua tais debates, podemos começar a transformar atitudes e mudar posicionamentos, como vemos no excerto 10 .

[10] Everybody has a different idea of the perfect body image, but we are influenced most of the time by the social media, pressuring on how to build the "perfect body". But this society expectation about the idea of the perfect body can cause a lot of problems. We see that on TV shows, magazines, telling us what type of body we should have, but the truth is that we forget people come in all different shapes and sizes and anyone can be attractive. All we need to do is take care of our health, and the type of food we eat, do exercises, and understand that sometimes what we see on TV is not healthy for everybody. (Nicky - produção textual)

No começo do nosso debate, Nicky afirma querer um aspirador de pó, dando a entender que se importa com a imagem da mulher, não somente a saúde. Em sua produção textual, ela retoma seu posicionamento e ressalta que os padrões de beleza devem ser encarados com mais distanciamento e menos rigor, afinal, os seres humanos são distintos. Ela acrescenta que a saúde e o bem estar físico devem ser considerados antes do ideal plástico do tempo em que se vive. A ênfase no ser e não no parecer foi ratificada pelo texto seguinte, utilizado em uma outra aula, mas conectado, de certa forma, à ideia debatida neste dia. Nesse sentido, podemos afirmar que a ideia de Nicky possa ser, de um certo modo, algo a debater.

No texto seguinte, vídeo 2, uma mulher sofre intervenções em seu corpo passando por diferentes formatos idealizados de beleza através dos tempos. 


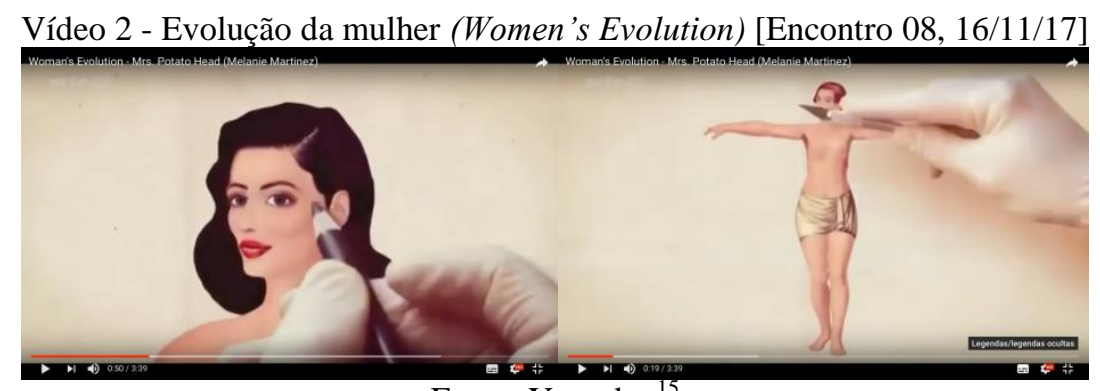

Fonte: Youtube.

No vídeo o corpo feminino é marcado, alterado, mutilado para se adequar ao que é esperado da sociedade para obter aceitação e ser percebida com admiração. Nas palavras de Perrot, "no palco do teatro, nos muros da cidade, a mulher é o espetáculo do homem. [...] Ainda hoje, o corpo feminino, silencioso e dissecado, continua sendo o principal suporte da publicidade" (PERROT, 2003, p. 14-15). A discussão que sucede ao vídeo ecoa este pensamento.

[11] No vídeo mostra uma mulher fantoche que é toda modificada para ser um ideal de mulher para alguns. Vejo que esse "ser fantoche" acontece muito no meio artístico e tem lugares com essa cultura fútil do corpo ideal que a mídia deseja pregar. Muitas pessoas são tão influenciadas por essas modas que se perdem em quem realmente são. Se perdem dentro de si e quando se dão conta já é tarde demais, o importante é não nos perdermos nas modas que só servem para deturpar a real imagem do ser humano. (Maria - Produção textual)

Em seu texto, Maria se opõe à superficialidade com que a sociedade trata da aparência feminina. Ao ler se lendo, Maria desafia as construções e convenções sociais sobre padrões de beleza feminina já naturatlizados. A aluna constrói uma interpretação que se beneficia do dissenso mostrando que "no Letramento Crítico a língua assume um caráter libertador, pois é por intermédio do controle e da crítica aos significados imbuídos no discurso e pela criação de um discurso alternativo que se daria a construção do cidadão consciente (CERVETTI; PARDALES; DAMICO, 2001 apud MATTOS; VALÉRIO, 2010, p. 139).

\section{REFLEXÕES FINAIS}

Por ser um projeto de extensão universitária, o centro de idiomas, onde geramos nosso material empírico, tem a missão de levar à comunidade a oportunidade de

\footnotetext{
${ }^{15}$ Disponível em: https://www.youtube.com/watch?v=OD2XOXowWiY. Acesso em: 10 out. 2015.
} 
frequentar os espaços acadêmicos e se beneficiar dos saberes científicos produzidos na universidade. Por meio desta experiência, podemos afirmar que os/as participantes deste estudo viveram mais que isso, haja vista teremsido agentes no processo de (des/re)construção de sentidos, levando consigo mais do que buscavam inicialmente aprimoramento nas habilidades linguísticas. Por meio das aulas os/as aprendizes puderam compartilhar ideias e refletir sobre questões que permeiam e formam suas vidas em sociedade.

Retomando os questionamentos que nos impulsionaram neste estudo, é possível afirmar que trabalhar com temas críticos vivenciais, ou temas 'prenhes de vida' (REZENDE, 2017) oportuniza o engajamento linguístico e crítico de aprendizes nas discussões em aulas de ínglês como língua adicional. Iniciamos este texto retomando a acepção de crítico como prática problematizadora que implica sujeitos em processos de autoquestionamento, busca por equidade, respeito e justiça social e finalizamos podendo afirmar que a educação linguística crítica pode ser determinante para ampliar o protagonismo discente bem como para que haja maior implicação dos/as aprendizes com seu processo de aprendizagem. As leituras e os debates propostos, permitiram que ao ler se lendo, como propõe Menezes de Souza (2011), os/as aprendizes pudessem revisitar sua prática e ressignificar seus saberes. O debate, aberto na sequência do visionamento das imagens, possibilitou que possíveis ideias cristalizadas mantidas pelos/as estudantes fossem revisitadas e seus sentidos deslocados.

Martins e Souza afirmam "que é por meio da reflexão que suas ações podem se tornar mais conscientes" (MARTINS; SOUZA 2015, p. 61). De igual maneira, também buscávamos oportunizar uma reflexão que se desafiarem os/as aprendizes em busca de sentidos outros que visem desnaturalizar comportamentos linguísticos e sociais que reforçam preconceitos, discriminação e injustiças.

A partir do visionamento e do debate de textos multimodais favorecemos que ideias (re)produzidas no "modo automático", como padrões estéticos e hábitos de consumo de tecnologias digitais e fossem reformuladas, e passamos a produzir juntos, professora e alunos/as novos sentidos. Ao abordar o contexto de formação de professores de línguas, Sabota e Silvestre afirmam que partindo "da reflexão sobre a prática, se pode chegar à reflexão crítica, uma vez que a sala de aula é um contexto micro com questões sociais tão relevantes e possíveis de receber olhares críticos quanto o contexto macro em que está inserido" (SABOTA; SILVESTRE 2017, p. 26). Esta 
afirmação se aplica também a este estudo. Por meio desta pesquisa que visava a educação linguística crítica por meio de temas crítico vivenciais os/as aprendizes puderam experimentar estudar inglêsde um modo que transcende o estudo da estrutura linguística e amplia seus repertórios linguísticos e interpretativos. Como professoras e pesquisadoras tivemos a grata sensação de contribuir para a formação linguística e, sobretudo, humana desses alunos.

\section{REFERÊNCIAS}

ARAGÃO, R. Cognição, emoção e reflexão na sala de aula: por uma abordagem sistêmica do ensino/aprendizagem de inglês. Revista Brasileira de Linguística Aplicada, v. 5, n. 2, p. 101-120, 2005.

CERVETTI, G.; PARDALES, M. J.; DAMICO, J. S. A tale of differences: comparing the traditions, perspectives and educational goals of critical reading and critical literacy. Reading Online, v. 4, n. 9, 2001.

FERREIRA, A. Formação de professores: raça/etnia. Cascavel: Coluna do Saber, 2006.

FREITAS, M. T. Teaching to transgress: Reflections on Critical Foreign Language/English Teaching. Trab. Ling. Aplic., Campinas, n (51.1): 77-98, jan./jun, p. 77-97, 2012.

GARCÍA, O.; WEI, L. Translanguaging, bilingualism, and bilingual education. The handbook of bilingual and multilingual education, p. 223-240, 2015.

HOOKS, B. Ensinando a transgredir: a educação como prática de liberdade / bell hooks: tradução de Marcelo Brandão Cipolla. - São Paulo: Editora WMF Martins Fontes, 2013. Título original: Teaching to Transgress: education as the practice of freedom.

JORDÃO, C. M. ILA- ILF - ILE - ILG : quem dá conta? Revista Brasileira de Linguística Aplicada, v. 14. p. 13-40, 2014.

JORDÃO, C. M. Abordagem comunicativa, pedagogia crítica e letramento crítico farinhas do mesmo saco? In: Rocha, C. H.; Maciel, R. F. (Org.). Língua Estrangeira e Formação Cidadã: entre discursos e práticas. 1ed. Campinas: Pontes, v. 1, p. 69-91, 2013.

JORDÃO, C. M. O Ensino de Línguas Estrangeiras - de código a discurso. In: VAZ BONI, V. (Org.). Tendências Contemporâneas no Ensino de Línguas. União da Vitória: Kaygangue, p. 1-9, 2006. 
LIER, L. V. Agency in the Classroom. In: LANTOLF, J. P.; POEHNER, M. E. (Eds.). Sociocultural theory and the teaching of second languages, London: Equinox, p. 1-7, 2008.

LUKE, A.; DOOLEY, K. Critical literacy and second language learning. In: HINKEL, E. (Ed.). Handbook of Research in Second Language Teaching and Learning (Vol. II). New York: Routledge, 2009.

MATTOS, A.; VALÉRIO, K. Letramento crítico e ensino comunicativo: lacunas e interseções. Revista Brasileira de Linguística Aplicada, v. 10, n. 1, 2010.

MARTINS, S.; SOUZA, N.; ARAGÃO, R. O papel das emoções e da Linguística Aplicada Crítica na Formação do Professor de Línguas. Anais do International Congress of Critical Applied Linguistics (ICCAL). Brasília: ICCAL, p. 59-73, 2015.

MATURANA, H. Emoções e Linguagem na educação e na política. Belo Horizonte: Editora UFMG, 1998.

MENEZES DE SOUZA, L. M. Para uma redefinição de Letramento Crítico: conflito e produção de significado. In: MACIEL, R. F.; ARAÚJO, V. A. (orgs). Formação de professores de línguas: ampliando perspectivas. Jundiaí: Paco Editorial, p. 129-139, 2011.

MONTE MOR, W. Letramentos críticos e expansão de perspectivas: diálogo sobre práticas. In: JORDÃO, C.; MARTINEZ, J. Z.; MONTE MOR, W. (Org.). Letramentos em Prática na Formação Inicial de Professores de Inglês. 1ed. Campinas, SP: Pontes Editores, v. 1, p. 315-335, 2018.

OLIVEIRA, S. Texto visual e leitura crítica: o dito, o omitido, o sugerido. Linguagem \&Ensino, Pelotas, Brasília. v. 9, n. 1, p. 15-39, jan./jun. 2006.

PENNYCOOK, A. Critical Applied Linguistics: a critical introduction. New Jersey: Lawrence Erlbaum Associates, 2001.

PERROT, M. Os silêncios do corpo da mulher. In: SOIHET, Rachel; MATOS, Maria Izilda S. O corpo feminino em debate. São Paulo: Editora UNESP, v. 1, 2003.

REZENDE, T. Posfácio. In: SILVESTRE, Viviane P. V. Colaboração e crítica na formação de professores/as de línguas: teorizações construídas em uma experiência com o PIBID. Campinas: Pontes, p. 279-289, 2017.

ROBSON, C. Real world research. Oxford: Blackwell Publishing, 1993.

SABOTA, B.; SILVESTRE, V. (orgs.). Pesquisa-ação \& formação: convergências no estágio supervisionado de língua inglesa - Anápolis: Editora UEG, 2017.

SABOTA, B.; SILVA, H.; ALMEIDA, R. Sobre o que vamos falar hoje?! Educação linguística crítica em LE/LA e a escolha de temas para debate em aula de inglês. In: 


\section{Dossiê Especial FICLLA}

REVISTA X, Curitiba, volume 14, n.5, p. 222-243, 2019

FERRAZ, D.; KAWACHI-FURLAN, C. J. (Org.). Educação Linguística em Línguas Estrangeiras.Campinas: Pontes Editora, v. 1, p. 87-106, 2018.

SILVESTRE, V. Teaching and Learning a Foreign/Additional Language at School: Relating Critical Perspectives to a Local Practice. RBLA, Belo Horizonte, v. 15, n. 1, p. 61-84, 2014.

SILVESTRE, V. Colaboração e crítica na formação de professores/as de línguas: teorizações construídas em uma experiência com o PIBID. Campinas: Pontes, 2017. 